\title{
Mean Platelet Volume and Prognosis of Unstable Angina
}

\author{
Tarek M. Abdel-Rahman \\ Cardiology Department, El Minia University Hospital, Minya, Egypt \\ Email: tarekabdelrahman211@yahoo.com
}

Received 14 January 2015; accepted 6 February 2015; published 15 February 2015

Copyright (C) 2015 by author and Scientific Research Publishing Inc.

This work is licensed under the Creative Commons Attribution International License (CC BY). http://creativecommons.org/licenses/by/4.0/

(c) $\underset{\mathrm{EY}}{\mathrm{i}}$ Open Access

\section{Abstract}

Objective: Clopidogrel therapy is the standard of care in patients with unstable angina. However, a percentage of subjects are nonresponders to clopidogrel and this leads to increased adverse outcome. On the other way round, some responsive patients are exposed to bleeding complications. Detection of both in daily practice is important in order to tailor the treatment protocol. In this study we aimed to estimate the cutoff value of mean platelet volume (MPV) for both platelet responsiveness and bleeding risks. Methods: The study was planned as a prospective cohort study. A total number of 230 patients admitted to our $\mathrm{CCU}$ with unstable angina over a period of one year (from June 2013 to May 2014) were enrolled. Exclusion criteria were: severe anemia, thrombocytopenia, myelodysplastic syndrome, coagulopathy and recent blood transfusion. In all patients clopidogrel was initially started and maintained during the hospital stay. Blood $(2 \mathrm{ml})$ was collected in dipotassium EDTA tubes from all patients on the first day of admission by a clean puncture. Samples for MPV analysis were drawn on admission, and analyzed within 1 hour of admission after sampling by Beckman Caulter LH 780 Analyzer. Grouping was then done according to MPV of the patients into group (I) who had a low MPV less than or equal to $7.00 \mathrm{fl}$, and group (II) with MPV equal to or higher than $9.00 \mathrm{fl}$. Demographical and clinical variables of the patients were recorded. Routine laboratory parameters were also recorded. Clinical manifestations during the admission period were meticulously reported. Major complications as bleeding or, urgent need for percutaneous coronary intervention (PCI) were also studied. Results: Among the 230 patients analyzed, 175 patients (76\%) were found to have MPV $\leq 7.00 \mathrm{fl}$ (group (I)) and 55 patients (24\%) had MPV $\geq 9.00 \mathrm{fl}$ (group (II)) with mean \pm SD MPV (8.4 $\pm 1.5 \mathrm{fl}$, vs $11.7 \pm 1.2 \mathrm{fl}$ respectively) (p < 0.001). Observation of clinical course during admission period revealed a statistically more significant clinical deterioration in group (II) than group (I) and the presence of more frequent AMI cases in group (II) having a high MPV. A high cutoff value of $9.7 \mathrm{fl}$ for MPV was detected in prediction of clopidogrel nonresponsiveness (group (II)) with a sensitivity of $78.2 \%$ and specificity of $66.8 \%$, and a low cutoff value for bleeding tendency lower than $6.3 \mathrm{fl}$ was detected in group (I) with a sensitivity of $71.4 \%$ and specificity of $62.5 \%$. Conclusion: This study showed that MPV can be used as a simple bed-side predictor for detection of clopidogrel response in patients with 
unstable angina. And a cutoff value for both platelet responsiveness and risk of bleeding is now reached. This may lead to enhancement in our decision for early intervention and attention for bleeding risk during clopidogrel therapy.

\title{
Keywords
}

\author{
Clopidogrel Resistance, Unstable Angina, Mean Platelet Volume
}

\section{Introduction}

Platelets are non-nucleated blood cells which play a crucial role in the process of coagulation. Their function is strongly associated with atherogenesis and atherothrombosis which are important in pathogenesis of cardiovascular diseases [1].

In the new millennium, coronary artery disease (CAD) is looming large as the new epidemic disease. Both endogenous and exogenous risk factors such as smoking, diabetes mellitus, hypertension, hypercholesterolaemia, mental stress, and obesity, acting either singly or in combination, significantly increase the chances of developing coronary atherosclerosis [2].

Platelets have been implicated in the pathogenesis of cardiovascular disorders, including atherosclerosis and its complications, such as acute myocardial infarction (AMI), unstable angina (UA), and sudden cardiac death. Platelet hyper-reactivity and local platelet activation have been suggested to play a causal role in acute coronary events [2].

Platelet size has been shown to reflect platelet activity. Large platelets are metabolically and enzymatically more active than small platelets and produce more thromboxane A2 [3] [4].

It is known that increased platelet volume is more reactive to higher concentration of active substances in microgranules (e.g. thromboxane A2 and B2, platelet factor 4, P-selectin, platelet-derived growth factor) and expression of adhesive receptors (glycoprotein IIb/IIIa) [5].

Furthermore, increased MPV values are associated with shortened bleeding time. MPV is a parameter which states platelet size and indirectly proves its activity [6].

Acetylsalicylic acid (ASA, aspirin) and ADP inhibitor-based therapy is well established in coronary artery disease treatment. Despite this treatment, platelet reactivity may remain high in some patients resulting in more frequent thrombotic complications in a syndrome widely known as high on-treatment platelet reactivity (HTPR) [7].

In recent years, new ADP inhibitors have become widely available. Although these new drugs undoubtedly decrease the risk of thrombotic complications, they also increase the risk of bleeding complications [8] [9].

In order to decrease the risk of both thrombotic and bleeding complications, it might be rational in some patients to tailor the antiplatelet treatment and on the other way round to focus at those who are unresponsive to it [10].

Many intrinsic and extrinsic factors associated with increased risk of HTPR have already been identified. We focused on conditions associated with high platelet turnover and increased ADP level. These risk factors are difficult to be measured exactly, but might be approximated by basic blood count values. Mean platelet volume is higher in younger and in activated platelets [11], and therefore can be expected to correlate with platelet turnover and platelet activation. Platelet count and platelet hematocrit correlate with a high level of platelet cytoplasm, which is known to be a source of potent pro-aggregatory substances [11].

ADPP2Y12 receptor interaction causes sustained activation of glycoprotein (GP) IIb/IIIa receptors leading to stable platelet-rich thrombus formation at the site of vessel wall injury [12].

Therefore clopidogrel whose active metabolite irreversibly inhibits the P2Y12 receptor is a cornerstone of oral antiplatelet therapy in the secondary prevention of coronary artery disease and in the immediate treatment of ACS and PCI. Addition of clopidogrel to aspirin therapy has been associated with better long-term clinical outcomes in patients undergoing PCI [13] [14].

The long-term clinical benefit associated with dual antiplatelet therapy has been also observed in patients with unstable angina and non-ST elevation myocardial infarction (STEMI) independent of coronary revascularization 
[15].

More recently clinical benefit of clopidogrel has also been extended to patients with STEMI [16] [17]. Despite the unambiguous clinical benefit achieved with the adjunct of clopidogrel in ACS/PCI patients, a considerable number of patients continue to have cardiovascular events. This has been attributed to variability of platelet response to clopidogrel therapy. Although the mechanism leading to poor clopidogrel effects is not fully elucidated and the best definition to assess antiplatelet drug response has not been fully established, there is sufficient evidence to support the persistence of enhanced platelet reactivity despite the use of clopidogrel is a clinically relevant entity [18].

Matetzky et al. (2004) demonstrated a strong relationship between clopidogrel nonresponsiveness and/or high on treatment platelet reactivity which was confirmed by multiple platelet assays and correlated to adverse clinical ischemic events [19].

However due to the lack of consensus on the optimal methods to quantify high platelet reactivity and the cutoff values associated with clinical risk, the routine measurement of platelet reactivity has not been widely implemented in clinical practice or recommended in the guidelines. As larger platelets are metabolically and enzymatically more active, and have greater prothrombotic potential, mean platelet volume (MPV) which is a routinely assessed marker is accepted as a potential measure of platelet reactivity [20].

However until now no study exists with a specific purpose of investigating the diagnostic accuracy of MPV test in prediction of either clopidogrel resistance or bleeding risk values.

Our aim was to study platelet mean volume in the spectrum of ischemic artery disease and make sense with clinicopathological correlation. Until MPV can reflect changes in either the level of platelet stimulation or the rate of platelet production, determination of cutoff values became essential for prediction of clopidogrel hyporesponsiveness and bleeding risk.

\section{Patients and Methods}

\section{Study design:}

This study was designed as a prospective cohort study for estimating the diagnostic accuracy of MPV in determining the course and prognosis of patients with unstable angina.

\section{Study protocol:}

A total number of 230 patients admitted to our CCU with unstable angina over a period of one year (from June 2013 till May 2014) in cardiology department of El-Minia university hospital. Institutional ethical committee clearance was obtained. All of the participants gave written informed consent.

Patients with severe anemia, thrombocytopenia, myelodysplastic syndrome, coagulopathy and recent blood transfusion were excluded.

In the whole population, clopidogrel was initially started. On admission a loading dose of $300 \mathrm{mg}$ was applied to the patients and this was followed by $75 \mathrm{mg}$ daily dose regimen.

\section{MPV analysis:}

Blood (2 ml) was collected in dipotassium EDTA tubes from all the patients on the first day of admission by a clean puncture, avoiding bubbles and froth. The sample was run within two hours of venepuncture using the Sysmex K-4500 automated cell counter (TOA Electronics, Koebe, Japan). Samples for MPV analysis were drawn on admission, and analysed within 1 hour after sampling by Beckman Caulter LH 780 Analyzer.

\section{Grouping:}

Patients are then classified into two groups based on their MPV laboratory result from the first day of admission into:

Group (I): were 175 patients with MPV $\leq 7.00 \mathrm{fl}$ and,

Group (II): were 55 patients with MPV $\geq 9.00 \mathrm{fl}$.

Study variables:

Demographical and clinical variables of the patients were recorded including age, sex, body mass index, diabetes mellitus, hypertension and smoking status.

Routine laboratory parameters were also recorded which were consisted of hemoglobin, total platelet count, MPV, CRP, HDL, LDL, triglyceride, AST, ALT, troponin level (cT-nI) and creatinine. Creatinine clearance of each patient was calculated by Cockroft-Gault formula. Concomitant drug therapy of the patients was also recorded. 
Clinical manifestations were recorded during the admission period as regards persistent chest pain (more than 30 minute), new onset mitral regurgitation (MR), manifestations of heart failure (HF), ST-segment elevation, acute myocardial infarction (AMI) and arrhythmias.

Major complications as bleeding and urgent need for percutaneous coronary intervention (PCI) are recorded and meticulously studied.

Statistical analysis:

Data was presented as numbers and frequencies for categorical variables, and mean \pm standard deviation or median values for continuous variables. The continuous variables were analyzed for normality. $\mathrm{P}$ value less than 0.05 was considered statistically significant. The Pearson correlation coefficient was computed to examine the association between two continuous variables. ROC curve analysis was used for definition of cutoff value for MPV in predicting clopidogrel hyporesponsiveness.

The value with highest sensitivity and specificity was assessed as the cut-off value. Statistical tests were performed using SPSS version 15 (SPSS).

\section{Results}

After collections of all patient's data, a comparison of demographic and medications used were tabulated and compared in Table 1 (comparison between demographic and medications used in the two groups).

The results revealed, there's no statistical differences between groups in demographic features except for age, as group (II) were significantly younger. Also, a higher percentage in group (II) needs thrombolytic therapy and diuretics.

Laboratory results are listed and compared between the groups in Table 2 (results of laboratory findings in both groups).

The Table 2, revealed, a significant statistical difference between groups was found in the form of higher MPV, CRP in group (II) versus group (I). Significant high TC, LDL, TG and lower HDL in group (II) than group (I). Also, a higher troponin level in group (II) than group (I).

The clinical course of the cases during admission period is listed and compared in Table 3 (results of clinical findings of both groups).

A statistical significance was found in all clinical manifestations during the admission course between both groups ( $\mathrm{P}=0.001)$ in the form of prolonged chest pain, appearance of new MR, HF and arrhythmias in group (II) with significantly lower numbers of ST-segment elevation and AMI in group (I).

Table 1. Comparison of demographic data and medications.

\begin{tabular}{|c|c|c|c|c|}
\hline \multirow{5}{*}{ Demographic } & Parameter & Group (I): N = 175 (76\%) & Group (II): N = 55 (24\%) & $\mathbf{P}$ \\
\hline & Age (yrs) & $56 \pm 4$ & $50 \pm 2$ & 0.01 \\
\hline & Height (cm) & $170 \pm 4$ & $167 \pm 6$ & NS \\
\hline & Weight (kg) & $90 \pm 2$ & $86 \pm 4$ & NS \\
\hline & $\operatorname{BMI}\left(\mathrm{kg} / \mathrm{m}^{2}\right)$ & $32 \pm 2$ & $31 \pm 3$ & NS \\
\hline \multirow{11}{*}{ Medications } & Gender male, n (\%) & $133(76 \%)$ & $98(80 \%)$ & NS \\
\hline & ASA, n (\%) & $175(100 \%)$ & $55(100 \%)$ & NS \\
\hline & Clopidogrel, n (\%) & $175(100 \%)$ & $55(100 \%)$ & NS \\
\hline & ACEI, n (\%) & 147 (84\%) & $46(85 \%)$ & NS \\
\hline & ARB, n (\%) & $28(16 \%)$ & $8(15 \%)$ & NS \\
\hline & B-Blockers, n (\%) & 155 (89\%) & $48(87 \%)$ & NS \\
\hline & CCB, n (\%) & $23(13 \%)$ & $7(14 \%)$ & NS \\
\hline & Statin, n (\%) & 161 (92\%) & $50(91 \%)$ & NS \\
\hline & Diuretics, n (\%) & 98 (56\%) & $40(74 \%)$ & 0.01 \\
\hline & OAD/Insulin, n (\%) & $136(78 \%)$ & $42(77 \%)$ & NS \\
\hline & Need for SK-therapy & $0.00(0 \%)$ & $43(78 \%)$ & 0.01 \\
\hline
\end{tabular}


Table 2. Laboratory findings in both groups.

\begin{tabular}{|c|c|c|c|}
\hline Laboratory findings & Group (I) $(\mathrm{N}=175)$ & Group (II) $(\mathrm{N}=55)$ & $P$ value \\
\hline Hemoglobin (gm \%) & $12 \pm 0.8$ & $13 \pm 0.5$ & NS \\
\hline Total platelet count $(\mathrm{p} / \mathrm{mcl})$ & $288 \pm 20$ & $292 \pm 16$ & NS \\
\hline Mean platelet volume (fl) & $8.4 \pm 1.5$ & $11.7 \pm 1.2$ & 0.001 \\
\hline C-reactive protein (CRP) mg/l & $4.5 \pm 1.0$ & $6.4 \pm 1.6$ & 0.001 \\
\hline Total cholesterol (TC) mg/dl & $183 \pm 28$ & $228 \pm 31$ & 0.001 \\
\hline Low density lipoprotein (LDL) mg/dl & $116 \pm 12$ & $160 \pm 6$ & 0.001 \\
\hline High density lipoprotein (LDL) mg/dl & $48 \pm 4.0$ & $36 \pm 3$ & 0.001 \\
\hline Triglyceride (TG) mg/dl & $168 \pm 14$ & $190 \pm 12$ & 0.001 \\
\hline SGOT (AST) unit/l & $25 \pm 5$ & $26 \pm 4$ & NS \\
\hline SGPT (ALT) unit/l & $44 \pm 2$ & $46 \pm 4$ & 0.08 \\
\hline Troponin level (cT-nI) ng/ml & $0.05+0.02$ & $0.25+0.15$ & 0.001 \\
\hline Creatinine clearance (CC) ml/m & $96+8$ & $94 \pm 9$ & NS \\
\hline
\end{tabular}

Table 3. Comparison of clinical findings between both groups.

\begin{tabular}{cccc}
\hline Clinical findings & Group (I) (N = 175) & Group (II) (N = 55) & P value \\
\hline Persistence of chest pain (n, \%) & $31(18 \%)$ & $48(88 \%)$ & 0.001 \\
New onset MR (n, \%) & $7(4 \%)$ & $29(54 \%)$ & 0.001 \\
Manifestation of HF (n, \%) & $4(2.3 \%)$ & $24(44 \%)$ & 0.001 \\
ST-segment elevation (n, \%) & $81(46 \%)$ & $43(78 \%)$ & 0.001 \\
Acute myocardial infarction (n, \%) & $47(26.8 \%)$ & $26(47 \%)$ & 0.001 \\
Arrhythmias (n, \%) & $4(2.3 \%)$ & $15(28 \%)$ & 0.001 \\
\hline
\end{tabular}

Bleeding complications were found in four cases in group (I) representing (2.3\%) of the total group and laboratory finding in their tests revealed a lower MPV than $6.5 \mathrm{fl}$ as shown in Figure 1.

Some patients in group-I exposed to bleeding tendencies, they are listed in Figure 1 (percentage of bleeding tendency).

Urgent intervention was needed in 12 patient in group (II) and representing 21.8\% of the total group population as shown in Figure 2 (percentage of patients needed urgent interventions).

A correlation was made between MPV and chest pain duration, revealed a strong positive linear relation with ( $r=0.9$ and $P=0.001)$ as shown in Figure 3 (correlation between MPV and chest pain duration).

A correlation was made between MPV and CRP and revealed a strong positive linear relation with $(r=0.92$ and $\mathrm{P}=0.001$ ) as shown in Figure 4 (correlation between CRP and MPV).

Trial to make a cut-off value was best done using ROC-curve as shown in Figure 5, and the group (I) found that a lower cutoff for bleeding tendency is $6.3 \mathrm{fl}$ with area under the curve 0.763 .

Statistical analysis using ROC-curve used for platelet non-responsive to clopidogrel therapy in group (II), as shown, in Figure 6, that revealed a higher platelet cutoff is $9.7 \mathrm{fl}$ with area under the curve 0.84 .

\section{Discussion}

Platelets are formed in the bone marrow from the polyploid megakaryocytes. Their volume is regulated by molecular mechanisms and growth factors and doesn't correlate with the age of platelets. It is influenced by thrombopoietin (TPO), interleukin-6 and -3 [21].

TPO is a main regulator of megakaryocytopoiesis. It also stimulates alpha granule secretion from platelets and enhances their ability to aggregate [22]. TPO was positively correlated with MPV in ACS patients in the report of Senaran et al. [23]. 
Bleeding complication in group (I)

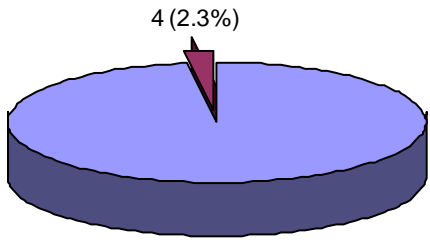

$171(97.7 \%)$

Figure 1. Percentage of bleeding tendency in patients of group (I).

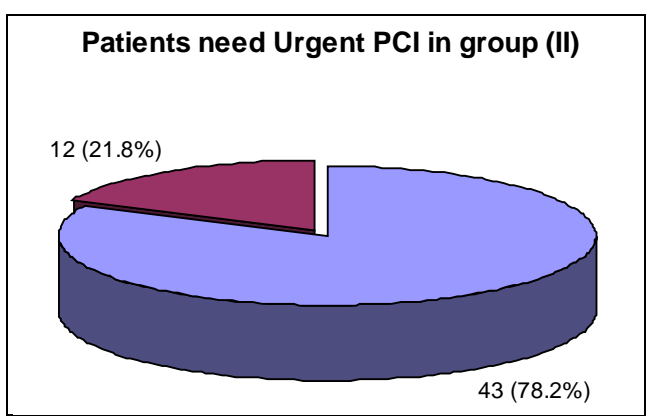

Figure 2. Percentage of patients need intervention in group (II).

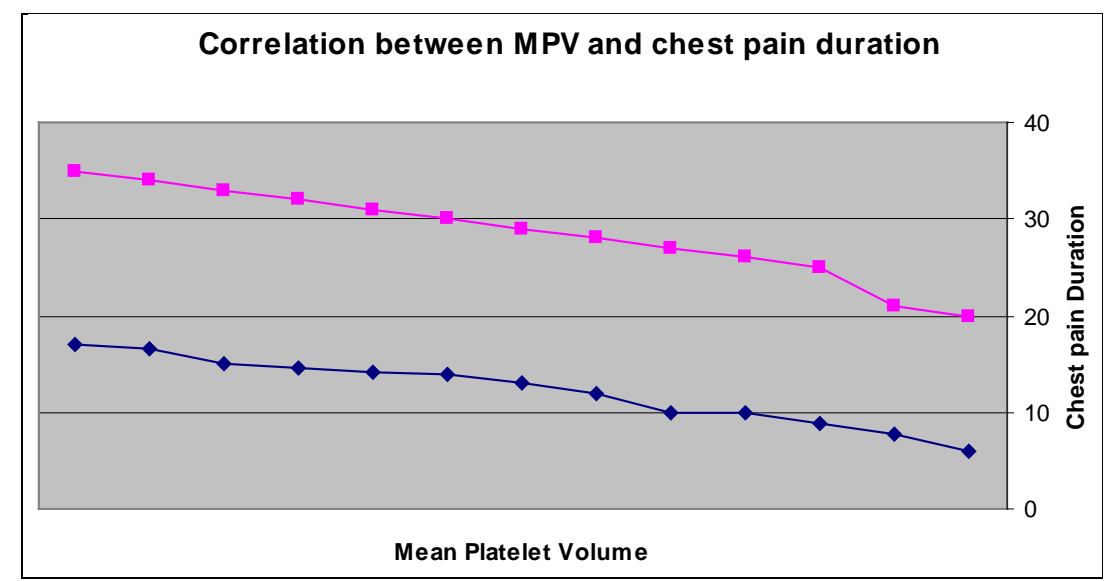

Figure 3. Correlation between MPV and chest pain duration.

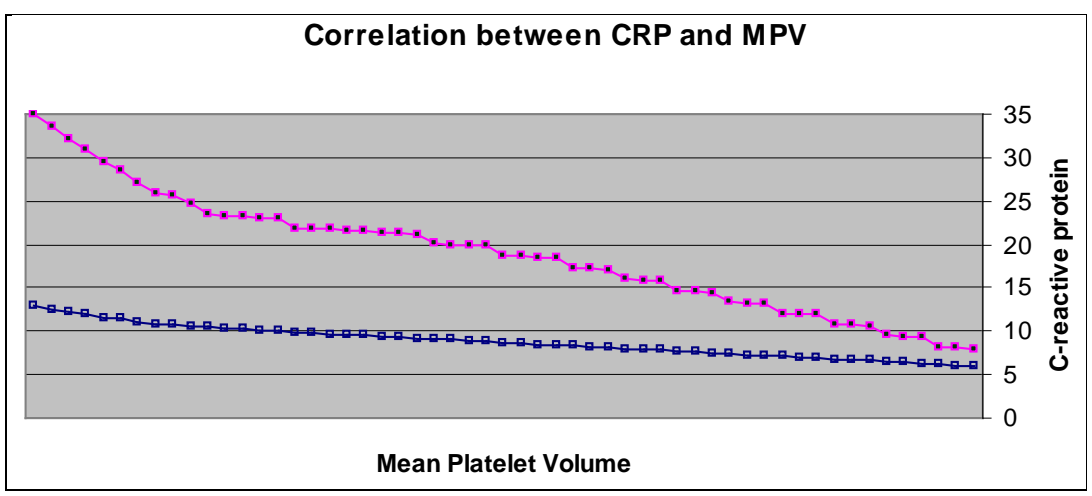

Figure 4. Correlation between MPV and C-reactive protein. 


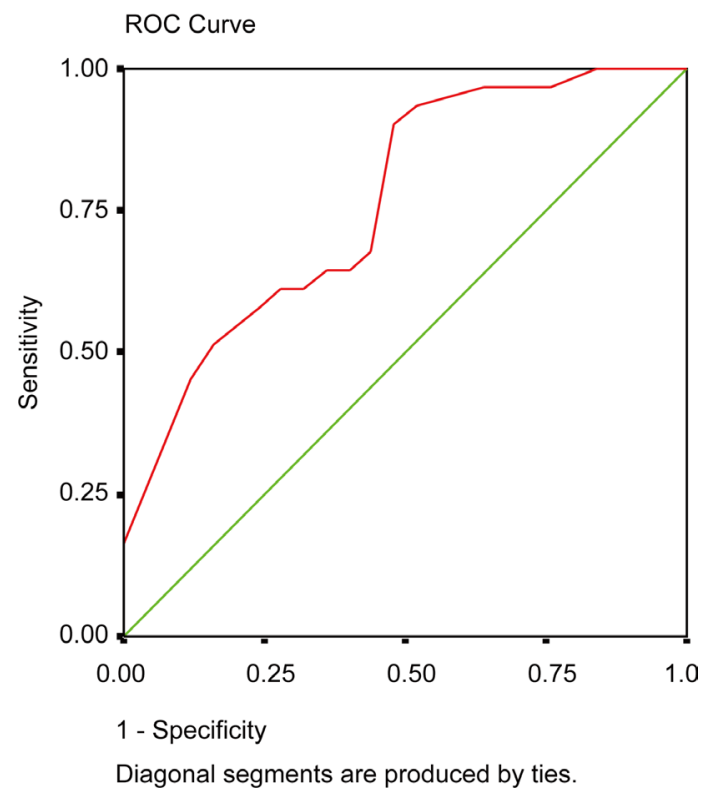

Figure 5. Roc curve analysis for bleeding complication in group (I).

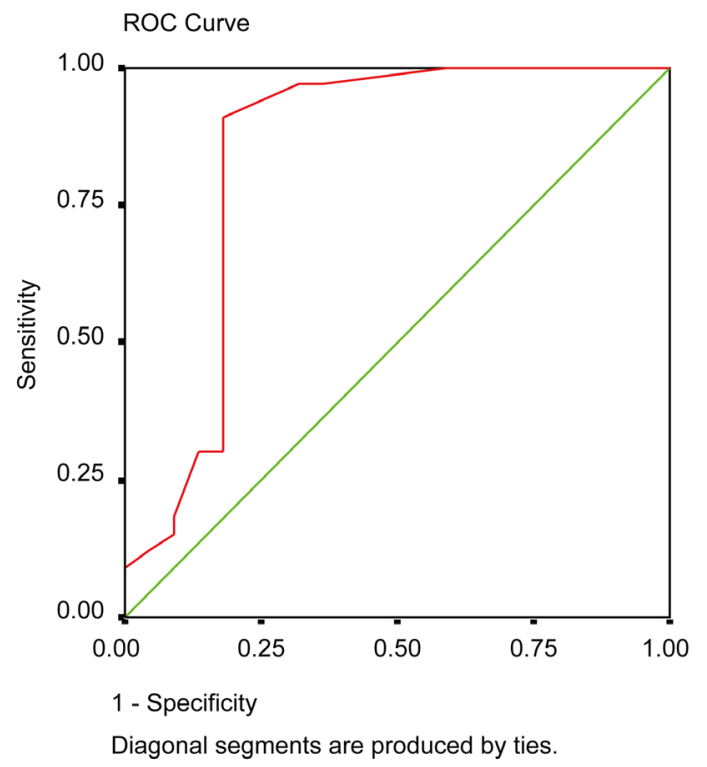

Figure 6. Roc curve analysis for platelet non-responsive to clopidogrel therapy in group (II).

MPV is considered a useful prognostic marker of cardiovascular risk. In general population, higher MPV value is associated with increased occurrence of myocardial infarction (MI) [24]-[26].

Considering the great prevalence of clopidogrel resistance and associated adverse outcomes, early recognition of these patients is very important. However the major problem in this issue is the lack of standardized method and cut-off values in definition of clopidogrel hyporesponsiveness. Several methods have been used but none of these, have been fully standardized or fully agreed upon to measure clopidogrel responsiveness [27].

Many intrinsic and extrinsic factors play role in determining platelet volume, In our study, we found a significant increased MPV in younger populations and this was similar to results made by Corash et al. [3], who confirmed increased MPV and its hyperactivity in younger than older patients. 
Moreover, a strong statistical difference between the two groups in relation to their lipograms, this was reflected on their worse outcome in patients having higher MPV (group (II)) and this might point to an independent risk between MPV and poor prognosis. This is confirmed by Klovaite et al. in 2011 [27] who found that, in general Danish population the risk of MI has increased by $38 \%$ in individuals with MPV $\geq 7.4$ vs $<7.4 \mathrm{fl}$ independently of known cardiovascular risk factors.

We concluded a strong correlation between MPV and C-reactive protein, and this point to its relation to inflammatory markers in acute phase of unstable angina. However, none has been documented this finding in myocardial ischemia, many studies document a strong relation between MPV and CRP in many infectious and inflammatory diseases [28] [29].

Increased MPV has been discussed recently as a predictor of death in patients with ACS, but the cutoff point of MPV in relation to poor prognosis has not been estimated so far [21] [22]. In our study, we tried meticulously to determine two cutoffs, one for bleeding tendency and other was for risk of poor outcome to medical therapy using ROC curves. We found that, a low cutoff MPV of equal or less than (6.2 fl) carry a risk of bleeding and a high cutoff $(9.7 \mathrm{fl})$ is linked to poor response to anti-platelet therapy.

In some studies conducted in AMI, elevated MPV was associated with higher risk of death and recurrent infarction not only in hospital but also during the 2 years observation after ACS [21] [29] [30].

Taglieri et al. 2011 [30] investigated higher risk of primary end-point, composed of cardiovascular death and re-MI at 1 year after ACS in patients with NSTEMI with MPV 8.9 fl. Chu et al. 2010 [21] reported the two-fold increase in mortality among acute MI patients with MPV cut off point of $10.3 \mathrm{fl}$ in comparison to a group with the cut-off point of $9 \mathrm{fl}$. In the study by Dogan et al. 2012 [26] major cardiac outcome (consisting of the composite end-point of cardiac death, MI, recurrent angina and hospitalization) in NSTEMI patients at 12 months was significantly higher in group with MPV $>9.9 \mathrm{fl}(39 \%$ vs $26 \%, \mathrm{P}=0.016)$.

\section{Conclusion}

This study showed that MPV can be used as a simple bed-side predictor for detection of clopidogrel response in patients with unstable angina. And a cutoff value for both platelet responsiveness and risk of bleeding is now reached. This may lead to enhancement in our decision for early intervention and attention for bleeding risk during clopidogrel therapy.

\section{References}

[1] Davi, G. and Patrono, C. (2007) Platelet Activation and Atherothrombosis. New England Journal of Medicine, 357, 2482-2494. http://dx.doi.org/10.1056/NEJMra071014

[2] Trip, M.D., Cats, V.K., van Capelle, F.J.L., et al. (1990) Platelet Hyperreactivity and Prognosis in Survivors of Myocardial Infarction. New England Journal of Medicine, 322, 1549-1554. http://dx.doi.org/10.1056/NEJM199005313222201

[3] Corash, L., Tan, H. and Grolnick, H.R. (1977) Heterogeneity of Human Whole Blood Platelet Subpopulations. I. Relationship between Buoyant Density, Cell Volume and Ultrastructure. Blood, 49, 71-87.

[4] Thompson, C.B., Eaton, K.A., Princiotta, S.M., et al. (1982) Size-Dependent Platelet Subpopulation: Relationship of Platelet Volume to Ultrastructure, Enzymatic Activity and Function. British Journal of Haematology, 50, 509-520. http://dx.doi.org/10.1111/j.1365-2141.1982.tb01947.x

[5] Huszek, Z., Kochman, J., Filipiak, K.J., et al. (2005) Mean Platelet Volume on Admission Predicts Impaired Reperfusion and Long Term Mortality in Acute Myocardial Infarction Treated with Primary Percutaneous Coronary Intervention. Journal of the American College of Cardiology, 46, 284-290. http://dx.doi.org/10.1016/j.jacc.2005.03.065

[6] Maden, O., Kacmaz, F., Selcuk, H., et al. (2009) Relationship of Admission Hematological Indexes with Myocardial Reperfusion Abnormalities in Acute ST Segment Elevation Myocardial Infarction Patients Treated with Primary Percutaneous Coronary Interventions. Canadian Journal of Cardiology, 25, e164-e168. http://dx.doi.org/10.1016/S0828-282X(09)70090-X

[7] Sibbing, D., Braun, S., Morath, T., Mehilli, J., Vogt, W., Schömig, A., et al. (2009) Platelet Reactivity after Clopidogrel Treatment Assessed with Point-of-Care Analysis and Early Drug-Eluting Stent Thrombosis. Journal of the American College of Cardiology, 53, 849-856. http://dx.doi.org/10.1016/j.jacc.2008.11.030

[8] Antman, E.M., Wiviott, S.D., Murphy, S.A., Voitk, J., Hasin, Y., Widimsky, P., et al. (2008) Early and Late Benefits of Prasugrel in Patients with Acute Coronary Syndromes Undergoing Percutaneous Coronary Intervention: A TRITONTIMI 38 (Trial to Assess Improvement in Therapeutic Outcomes by Optimizing Platelet Inhibition with Prasugrel- 
Thrombolysis in Myocardial Infarction) Analysis. Journal of the American College of Cardiology, 51, 2028-2033. http://dx.doi.org/10.1016/j.jacc.2008.04.002

[9] Cannon, C.P., Harrington, R.A., James, S., Ardissino, D., Becker, R.C., Emanuelsson, H., et al. (2010) Comparison of Ticagrelor with Clopidogrel in Patients with a Planned Invasive Strategy for Acute Coronary Syndromes: (PLATO): A Randomised Double-Blind Study. Lancet, 375, 283-293. http://dx.doi.org/10.1016/S0140-6736(09)62191-7

[10] Siller-Matula, J.M., Francesconi, M., Dechant, C., Jilma, B., Maurer, G., Delle-Karth, G., et al. (2013) Personalized Antiplatelet Treatment after Percutaneous Coronary Intervention: The MADONNA Study. International Journal of Cardiology, 167, 2018-2023. http://dx.doi.org/10.1016/j.ijcard.2012.05.040

[11] Corash, L., Chen, H.Y., Levin, J., Baker, G., Lu, H. and Mok, Y. (1987) Regulation of Thrombopoiesis: Effects of the Degree of Thrombocytopenia on Megakaryocyte Ploidy and Platelet Volume. Blood, 70, 177-185.

[12] Storey, R.F., Newby, L.J. and Heptinstall, S. (2001) Effects of P2Y(1) and P2Y(12) Receptor Antagonists on Platelet Aggregation Induced by Different Agonists in Human Whole Blood. Platelets, 12, 443-447. http://dx.doi.org/10.1080/09537100120085450

[13] Mehta, S.R., Yusuf, S., Peters, R.J., Bertrand, M.E., Lewis, B.S., Natarajan, M.K., et al., Clopidogrel in Unstable Angina to Prevent Recurrent Events Trial (CURE) Investigators (2001) Effects of Pretreatment with Clopidogrel and Aspirin Followed by Long-Term Therapy in Patients Undergoing Percutaneous Coronary Intervention: The PCI-CURE Study. Lancet, 358, 527-533. http://dx.doi.org/10.1016/S0140-6736(01)05701-4

[14] Steinhubl, S.R., Berger, P.B., Mann 3rd, J.T., Fry, E.T., DeLago, A., Wilmer, C., et al., Clopidogrel for the Reduction of Events during Observation (2002) Early and Sustained Dual Oral Antiplatelet Therapy Following Percutaneous Coronary Intervention: A Randomized Controlled Trial (CREDO). JAMA, 288, 2411-2420. http://dx.doi.org/10.1001/jama.288.19.2411

[15] Yusuf, S., Zhao, F., Mehta, S.R., Chrolavicius, S., Tognoni, G., Fox, K.K., et al. (2001) Effects of Clopidogrel in Addition to Aspirin in Patients with Acute Coronary Syndromes without ST-Segment Elevation. New England Journal of Medicine, 345, 494-502. http://dx.doi.org/10.1056/NEJMoa010746

[16] Sabatine, M.S., Cannon, C.P., Gibson, C.M., López-Sendón, J.L., Montalescot, G., Theroux, P., et al., CLARITYTIMI 28 Investigators (2005) Addition of Clopidogrel to Aspirin and Fibrinolytic Therapy for Myocardial Infarction with ST-Segment Elevation. New England Journal of Medicine, 352, 1179-1189. http://dx.doi.org/10.1056/NEJMoa050522

[17] Chen, Z.M., Jiang, L.X., Chen, Y.P., Peto, R., Collins, R., Jiang, L.X., et al., COMMIT (Clopidogrel and Metoprolol in Myocardial Infarction Trial) Collaborative Group (2005) Addition of Clopidogrel to Aspirin in 45,852 Patients with Acute Myocardial Infarction: Randomised Placebo-Controlled Trial. Lancet, 366, 1607-1621. http://dx.doi.org/10.1016/S0140-6736(05)67660-X

[18] Güray, Y., Güray, Ü. and Korkmaz, Ş. (2009) Clopidogrel Resistance. Anadolu Kardiyol Derg, 9, $231-237$.

[19] Matetzky, S., Shenkman, B., Guetta, V., Shechter, M., Beinart, R., Goldenberg, I., et al. (2004) Clopidogrel Resistance Is Associated with Increased Risk of Recurrent Atherothrombotic Events in Patients with Acute Myocardial Infarction. Circulation, 109, 3171-3175. http://dx.doi.org/10.1161/01.CIR.0000130846.46168.03

[20] Park, Y., Schone, N. and Harris, W. (2002) Mean Platelet Volume as an Indicator of Platelet Activation: Methodological Issues. Platelets, 13, 301-306. http://dx.doi.org/10.1080/095371002220148332

[21] Chu, S.G., Berger, R.C., Bhatt, D.L., Eikelboom, J.W., Konkle, B., Mohler, E.R., et al. (2010) Mean Platelet Volume as a Predictor of Cardiovascular Risk: A Systematic Review and Meta-Analysis. Journal of Thrombosis and Haemostasis, 8, 148-156. http://dx.doi.org/10.1111/j.1538-7836.2009.03584.x

[22] Deutsch, V. and Tomer, A. (2006) Megakaryocyte Development and Platelet Production. British Journal of Haematology, 134, 453-466. http://dx.doi.org/10.1111/j.1365-2141.2006.06215.x

[23] Senaran, H., Ileri, M., Altinbas, A., KoŞar, A., Yetkin, E., Öztürk, M., Karaaslan, Y. and Kirazli, Ş. (2001) Thrombopoietin and Mean Platelet Volume in Coronary Artery Disease. Clinical Cardiology, 24, 405-408. http://dx.doi.org/10.1002/clc.4960240511

[24] Yasar, A.S., Bilen, E., Yuksel, I., Arslantaş, U., Karakaş, F., Kirbaş, O. and Bilge, M. (2010) Association between Admission Mean Platelet Volume and Coronary Patency after Thrombolytic Therapy for Acute Myocardial Infarction. Turk Kardiyoloji Dernegi Arsivi, 38, 85-89.

[25] Martin, J.F., Bath, P.M. and Burr, M.L. (1991) Influence of Platelet Size on Outcome after Myocardial Infarction. Lancet, 338, 1409-1411. http://dx.doi.org/10.1016/0140-6736(91)92719-I

[26] Dogan, A., Aksoy, F., Icli, A., Arslan, A., Varol, E., Uysal, B.A., Ozaydin, M. and Erdogan, D. (2012) Mean Platelet Volume Is Associated with Culprit Lesion Severity and Cardiac Events in Acute Coronary Syndromes without ST Elevation. Blood Coagulation \& Fibrinolysis, 23, 324-330. http://dx.doi.org/10.1097/MBC.0b013e328352cb21

[27] Klovaite, J., Benn, M., Yazdanyar, S. and Nordestgaard, B.G. (2011) High Platelet Volume and Increased Risk of 
Myocardial Infarction: 39531 Participants from the General Population. Journal of Thrombosis and Haemostasis, 9, 49-56. http://dx.doi.org/10.1111/j.1538-7836.2010.04110.x

[28] Kuliczkowski, W., Witkowski, A., Polonski, L., Watala, C., Filipiak, K., Budaj, A., et al. (2009) Interindividual Variability in the Response to Oral Antiplatelet Drugs: A Position Paper of the Working Group on Antiplatelet Drugs Resistance Appointed by the Section of Cardiovascular Interventions of the Polish Cardiac Society, Endorsed by the Working Group on Thrombosis of the European Society of Cardiology. European Heart Journal, 30, 426-435. http://dx.doi.org/10.1093/eurheartj/ehn562

[29] Zareifar, S., Farahmand Far, M.R., Golfeshan, F. and Cohan, N. (2014) Changes in Platelet Count and Mean Platelet Volume during Infectious and Inflammatory Disease and Their Correlation with ESR and CRP. Journal of Clinical Laboratory Analysis, 28, 245-248. http://dx.doi.org/10.1002/jcla.21673

[30] Taglieri, N., Saia, F., Rapezi, C., Marrozzini, C., Bacchi Reggiani, M.L., Palmerini, T., et al. (2011) Prognostic Significance of Mean Platelet Volume on Admission in an Unselected Cohort of Patients with Non ST-Segment Elevation Acute Coronary Syndrome. Thrombosis and Haemostasis, 106, 132-140. http://dx.doi.org/10.1160/TH10-12-0821 
Scientific Research Publishing (SCIRP) is one of the largest Open Access journal publishers. It is currently publishing more than 200 open access, online, peer-reviewed journals covering a wide range of academic disciplines. SCIRP serves the worldwide academic communities and contributes to the progress and application of science with its publication.

Other selected journals from SCIRP are listed as below. Submit your manuscript to us via either submit@scirp.org or Online Submission Portal.
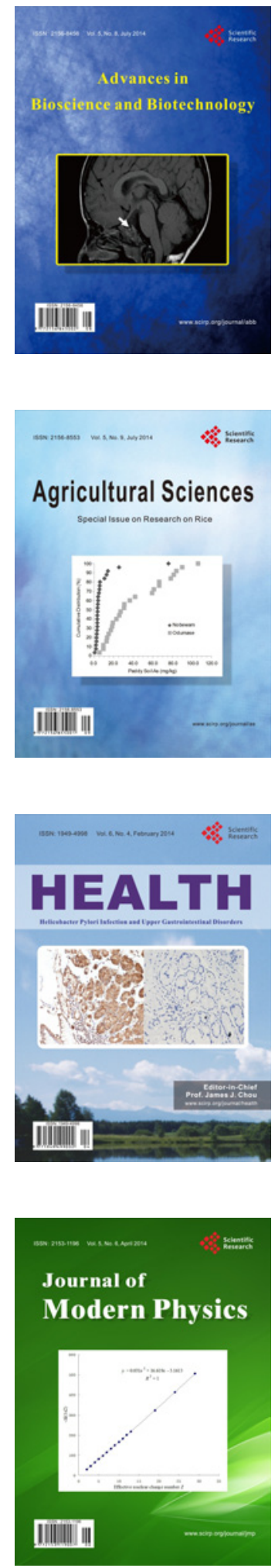
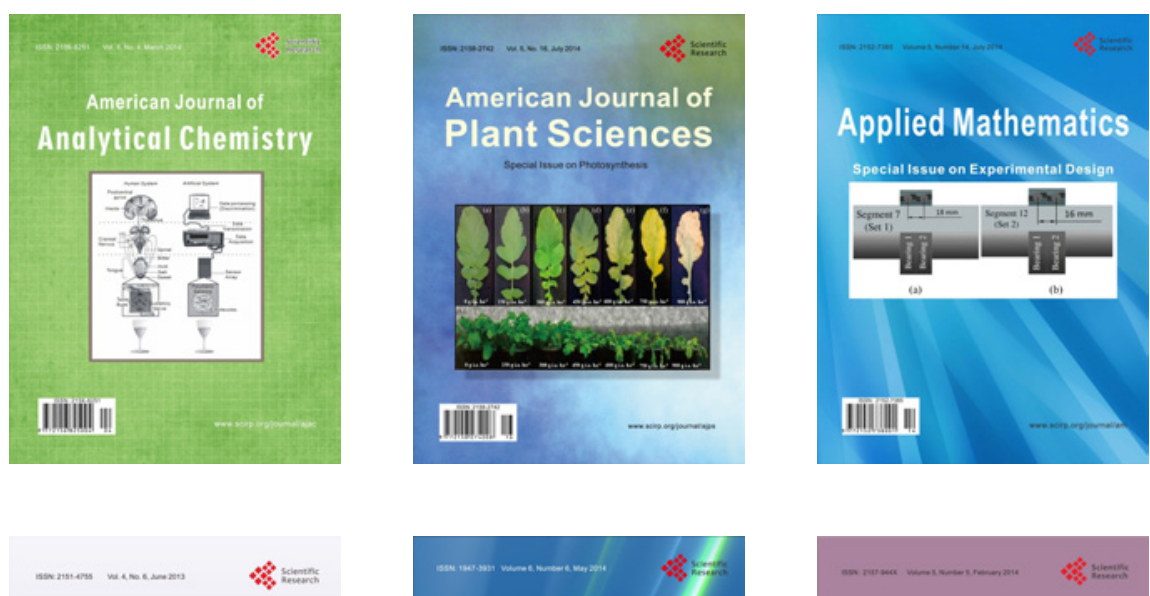

Creative Education
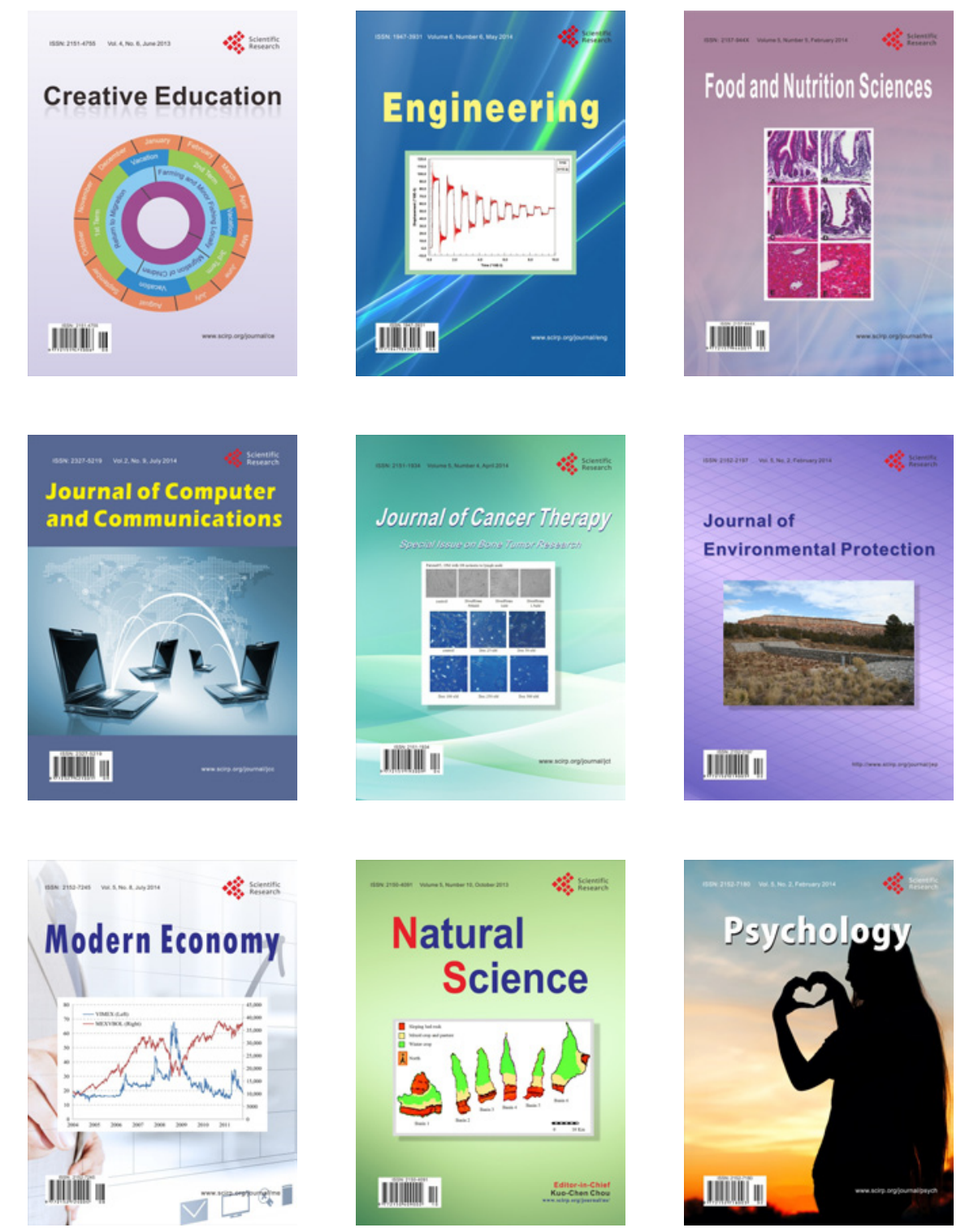